\title{
Curriculum Implementation in Zambia: Best Practices of Bridging the Gap between the Intended and the Achieved School Curriculum
}

\author{
Robert Changwe ${ }^{*} \&$ Christine Mwanza \\ The University of Zambia, School of Education, Department of Language and Social Sciences Education, P. O Box 32379, \\ Lusaka, ZAMBIA \\ *Corresponding Author
}

\begin{abstract}
Curriculum implementation is part and parcel of the curriculum development process. When curriculum developers intend to develop a curriculum, they are expected to put in place ways and means of having it implemented. Once this is ignored, all the good efforts and aspirations of curriculum developers as well as of the general public risk being wasted and misrepresented. Therefore, a very good curriculum is worthless if it cannot bring about the results of what it was intended for. Based on studies that have been done both locally and internationally, the authors of this paper attempted to give an analysis of barriers that may render a well-developed curriculum useless if appropriate remedies or simply best practices of bridging the gap between the intended and achieved curriculum are neglected in the education system of the country. Due to several impediments to the effective implementation of the school curriculum, it was recommended that the Zambian government needed to put in place best practices that would improve the quality of Zambian education by providing adequate funding to the education sector and this will in turn lead to the country's economic development. There was also a need for the Ministry of General Education to consider improving; the quality and quantity of the teaching staff, availability of school facilities and equipment as well as ensuring that time is appropriately managed for the good management of the curriculum.
\end{abstract}

Keywords: Curriculum impediments, curriculum development, curriculum implementation, intended curriculum, achieved curriculum.

\section{INTRODUCTION}

$\mathrm{M}$ atters of curriculum cuts across all areas wherever education issues are being discussed. It is impossible to talk about education without referring to curriculum issues, after all, it is a curriculum that brings about the achievement of all educational goals. It could be because of these grounds that Mulenga (2018) considered curriculum as a central business of every educational institution. Despite having several definitions of the concept curriculum in literature, Tanner and Tanner (1980: 25) defined curriculum as;

the planned and guided learning experiences and intended learning outcomes, formulated through the systematic reconstruction of knowledge and experience, under the auspices of the school, for the learner's continuous and willful growth in personal-social competence.
Mulenga (2018: 20) recognised the complexity and diversity of the concept curriculum and in trying to address different points of views surrounding the concept of curriculum, he defined curriculum as;

all the selected, organised, integrative, innovative and evaluative educational experiences provided to learners consciously or unconsciously under the school authority in order to achieve the designated learning outcomes which are achieved as a result of growth, maturation and learning meant to be best utilised for life in a changing society.

Based on various views of scholars surrounding the concept of curriculum and how it is linked to education, it is worthwhile noting that education and curriculum are inseparable. Besides, education is a universal human right and if anything, it is the best legacy a nation can ever give to its citizens. It should be out rightly stated that the country cannot provide quality education if its curriculum is not of good quality. Thus if the country is to boast about the quality provision of education it is vital to take a keen interest in curriculum development as well as its implementation because a very well-developed curriculum is worthless if it cannot be effectively implemented.

When a team of curriculum developers embark on curriculum development process, they always have good curriculum intent that is expected to be realised after the developed curriculum has been effectively implemented. Therefore, the intended curriculum refers to a set of formal documents which specify what relevant national education authorities and society expect teachers to teach learners in schools in terms of knowledge, values, skills and attitudes as well as how the outcomes of the teaching and learning process will be assessed (http://www.ibe.unesco.org/en/glossary-curriculumterminology/i/intended-curriculum). On the other hand, Ogula (1998) defined achieved curriculum as various experiences in terms of knowledge, values, skills and attitudes that are acquired by learners based on their interaction with the planned/intended curriculum. However, there seems to be a gap between the intended and the achieved curriculum in most countries including Zambia. Wanjiru (2008) defined 
curriculum implementation as a process of translating the officially prescribed subjects or courses of study by teachers into syllabuses, schemes of work, and lessons taught to learners at different levels. Besides, Okello and Kagoire (1996: 124) defined curriculum implementation as "a network of varying activities involved in translating curriculum designs into classroom activities and changing people's attitudes to accept and participate in these activities." Thus, curriculum implementation involves the correct interpretation of what is contained in official curricula documents and ensuring that they are effectively put into good practice.

When a curriculum is developed, it may have good knowledge, skills and values because of what a team of curriculum specialists could have considered in the process of its development, but by the time it leaves a team of curriculum developers' hands, its value keeps diminishing and by the time it reaches the teacher who is a curriculum implementer and eventually the learners who are the sole beneficiaries of the curriculum content, there are possibilities of having a good percentage of the original intent being misunderstood as well as misrepresented. It is against such a background that makes it inevitable to evaluate the implementation of the curriculum if the country's education system is to be relevant to its citizens as well as to incorporate innovations that may come as a result of technological advancements and new discoveries. It was thus, the intention of the authors of this paper to give an analysis of barriers that may render a welldeveloped curriculum useless if appropriate remedies or simply best practices of bridging the gap between the intended and achieved curriculum are neglected in the education system of the country.

\section{Barriers to Effective Implementation of the Curriculum}

In this section, various factors that are barriers to curriculum implementation in most developing countries have been unveiled as well as how the identified barriers can be levelled. Among the factors include: economic conditions of the country, availability of school facilities and equipment, quality and quantity of human resource, lack of motivation amongst curriculum implementers as well as lack of efficient management of time resource.

\section{ECONOMIC CONDITIONS}

The economy of the country is a fulcrum where the development of the country is centred. If a country has good economy supported by progressive educational policies, the education sector which is the engine of national development is likely to have its curriculum well developed and effectively implemented. The poor economy of the country would mean no adequate funding to all government ministries the education sector inclusive. When the Ministry of General Education is not handsomely funded, it entails: running schools without appropriate teaching and learning materials, lack of worthwhile in-service training, lack of monitoring of teaching and learning activities in schools by standards officers as well as many more cardinal things that are expected to be done for the smooth implementation of the curriculum. Sibulwa (1996) argued that poor economic conditions might lead to the education system not thriving because the increased number of human resource is likely to absorb all the funds available through salaries leaving very little for the purchase of appropriate teaching and learning materials. For instance, Kelly (1999) explained that it is impossible for teachers who have no materials for English comprehension to effectively teach the comprehension component which can be a big drawback on learners and the education system of the country.

Similarly, Nkosha and Mwanza (2009) asserted that it was impossible to accomplish the intentions of curriculum developers in the absence of appropriate teaching and learning materials. For instance, teachers need to have appropriate teaching and learning materials and learners too need to have adequate materials to refer to for comprehensive learning to take place. A very good example can be cited based on what transpired in Zambia when implementing the 2013 revised curriculum at junior secondary education in the year 2015. The government through the Ministry of General Education instructed all the schools in the country to start teaching as well as the Examination Council of Zambia to start examining learners in Computer Studies at Junior secondary education when in actual sense schools had both no qualified teachers and no well-stocked computer laboratories (Changwe and Mulenga, 2020). Such a scenario pushed school administration into panic mood where teachers with very basic knowledge about computers were requested to be teaching learners in order to fulfil the government directive. Besides, teachers had to move up and down trying to borrow computers to enable their learners to do practicals in Computer Studies. In most rural schools, practical examinations were conducted up-to mid-night due to inadequate computers and unreliable sources of power.

Although every teacher is expected to be resourceful to enable $\mathrm{him} /$ her to teach using the locally available resources, it is the duty of the government through the Ministry of General Education to ensure that all schools have qualified human resource and are adequately supplied with all the necessary teaching and learning materials such as textbooks, computers and many other relevant materials before the implementation of any developed/revised curriculum (Shiundu \& Omulando, 1992). Besides, Fullan and Pomfert (1977) acknowledged that one of the factors that adversely affects the achievements of the set curriculum objectives is the shortage of teaching and learning materials. Based on the arguments raised by various scholars, it can be summarised that when there is adequate funding and appropriate utilisation of government funds, schools would be in a position to have appropriate resources that would enhance effective implementation of the curriculum. 
It must be made clear that with good funding, standards officers countrywide would effectively monitor the implementation of the curriculum in schools. If there are serious gaps between the intended and the implemented curriculum, it is within the authority of standards officers to organise a regional or district seminar or conference so that the identified gaps can be adequately addressed by competent subject specialists. The other factors that may be linked to matters of the economy are discussed in the following subsections.

\subsection{Availability of School Facilities and Equipment}

Mkandawire (2010) considered unavailability of school facilities and equipment such as classrooms, libraries, resource centres, desks and school halls as critical impediments to curriculum implementation. Similarly, Kelly (1999: 196) described the Zambian school infrastructure as "dilapidated, unsafe and sometimes unusable." Psychology has shown that effective teaching and learning can only take place when the learning environment is conducive. It is therefore not clear how science practicals could be conducted at the school which has got neither good classrooms nor wellstocked science laboratories. It is such kind of learning environments that negate learners the practical part of their learning experience. Mkandawire (2010) further added that lack of adequate classrooms may lead to over enrolment and when a class has more than the required number of learners, teachers may not render individual learner attention which may eventually compromise on the quality of the education being provided.

One of the best practices of enhancing quality provision of education is to ensure that each and every school is provided with good and adequate infrastructure in terms of classrooms, libraries as well as well stocked laboratories. When the infrastructure is good and adequate, all learners are likely to sit comfortably and receive maximum individual attention from the teacher. It is such kind of learning environment that would improve learner achievements in several forms of assessments that learners may be subjected to in trying to check on the extent to which learning has taken place as well as the achievement of curricula intent.

\subsubsection{School Attendance versus Hunger}

The inadequacy of food stuffs in the country can as well negatively affect the implementation of the school curriculum as it can lead to malnutrition and mental retardation amongst learners. For instance, the consideration of Zambia amongst the hunger stricken countries is a serious issue that requires urgent remedies. It must be made clear that a learner who goes to school hungry cannot concentrate on anything that is being taught in school thereby widening the gap between the intended and achieved curriculum. The study by Omondi (2014) revealed that hunger and poor nutrition in Africa had brought about increased absenteeism amongst learners. Absenteeism of learners from school is a very serious obstacle to curriculum implementation as learners are not available to acquire the planned curriculum content hence leading to a wide gap between the intended and achieved curriculum. According to Zambia Daily Mail dated $27^{\text {th }}$ March, 2017, the permanent secretary in the Ministry of General Education by then Henry Tukombe explained that the government of the republic of Zambia had the intentions of implementing countrywide the feeding programme to all learners in pre-and primary schools. Based on the pilot study which involved 38 districts and 2700 pre-and primary schools, the results had indicated that the feeding programme had the potential to improve school attendance for a larger percentage of learners who stay away from school on account of hunger. If well implemented, this of course can be one of the best practices of bridging the gap between the intended and the achieved curriculum more especially in rural schools. Since 2017, it is still not very clear on the extent to which the feeding programme has been implemented in Zambian pre-and primary schools.

\subsection{The Quality and Quantity of the Teaching Staff}

Bishop (1985) contended that the quality of the teacher education curriculum determines the quality of the product of such a curriculum. The argument by Bishop is very important to reflect on if the country is to produce the crop of teachers who would effectively implement the school curriculum. Changwe (2017) attempted to authenticate Bishop's assertion by arguing that if the school curriculum is to be effectively implemented there was need for the teacher education curriculum to be aligned to the school curriculum. Thus, lack of quality teachers due to the quality of the teacher education curriculum is a serious impediment to the implementation of the school curriculum more especially in this era where there are a lot of mushrooming colleges of education and universities. Besides, national education policy documents have not remained mute on the quality of teachers graduating from higher institutions of learning and eventually managing Zambian schools. For instance, the MoE (1992) Focus on Learning documented that;

The quality of Zambian's schools reflected the quality of the teachers manning the schools, while the quality of the teachers reflects the effectiveness of the institutions that train them. The focus of concern in an effective teacher education institution is on transforming its students into competent and committed teachers. The programme for teacher education therefore, must be kept under constant review to ensure that it responds to the real needs of Zambian schools (MoE, 1992: 97).

This argument is true because it is impossible for the teacher to competently teach things that he/she does not understand. Despite having very good grades on their school certificates, this does not deduce that they can teach all the topics in the school curriculum. This is one of the reasons of aligning the teacher education curriculum to the school curriculum so that student teachers are given a special chance to understand 
various concepts which they did not know when they were learners in school (Changwe and Mulenga, 2018). It is during teacher education programme where student teachers are expected to be provided with worthwhile knowledge to enable them to be critical and analytical in explaining and justifying why various concepts/laws are the way they are in their subject of specialisation. This in a long run would reduce the mechanical ways of teaching learners at various levels in schools. Besides, the Higher Education Authority in collaboration with the Teaching Council of Zambia needed to take keen interest in closely monitoring what was prevailing in every higher institution of learning where teachers were being prepared to teach in schools.

Despite having not carried out a study in Zambia on the perceptions of teachers on the establishment of the Teaching Council of Zambia (TCZ), it is cardinal to argue that the establishment of the TCZ had so far played a very cardinal role in trying to regulate the professional conduct of teachers in the country as well as providing part of the solution to the old debate on whether teaching is a profession. Few years of its establishment in Zambia working in collaboration with the Teaching Service Commission, TCZ managed to get rid of a good number of teachers who had forged academic and professional qualifications out of the teaching fraternity. It was the hope of the author that the TCZ was likely to significantly contribute to the quality of the Zambian education system by ensuring that only qualified human resource is given the mandate of handling school going children at various grade levels.

In terms of the quantity of the teaching staff, it is clear that when the school is understaffed, a few available staff at school tend to be overloaded with a lot of work which in turn adversely affects the quality of the lessons taught to various learners (Mkandawire, 2010). In trying to address the problem of understaffing, school managements at times tend to employ teachers who may not have the right competences or who may come in after being seconded. In most cases, such teachers only teach what they are familiar with and leaving out other cardinal components of the curriculum where they lack adequate knowledge.

In Zambia, one of the areas that has greatly suffered in terms of staffing is the field of special education. It is not that the country does not have teachers who are specialised in teaching learners with special education needs, the major challenge could be that the few available teachers had been misplaced in schools where their competencies are not put to good use. This implies that there were artificial shortages of special education teachers in the country. Mkandawire (2010) explained that lack of adequate trained personnel to handle learners with special education needs acted as an impediment to effective implementation of the intended curricula. The solution to this problem is for the Ministry of General Education to ensure that adequate number of teachers are trained and strictly deployed to teach in special schools where their competencies were mostly needed.

In terms of the health of the teaching staff, Kelly (1999) argued that teachers' health is very vital for effective classroom teaching. He explained that teachers who frequently fall sick as a result of poor health conditions may not effectively implement the curriculum. Besides, learners who have patients at their homes may not as well concentrate and acquire the best education that they would want to get. Thus the health of the general public in the country more especially where there is rampant spread of HIV and AIDS as well as the so called Covid-19 amongst the work force may as well be an impediment to the appropriate implementation of the curriculum. The panacea to such an impediment is for the general public to play a role in stopping further spread of sexually transmitted infections and other human infection as well as to consider taking physical exercises as a hobby as a way of preventing non-communicable diseases. There is also need for the general public to strictly follow the Ministry of Health guidelines such as; observing the social distance, frequent washing of hands with soap or sanitise, correct wearing of the face masks as well as getting vaccinated as a way of combating the Coronavirus.

\subsection{Motivation among Curriculum Implementers}

Motivation is one of the key ingredients amongst curriculum implementers if a well-developed curriculum is to be effectively implemented. Mwanza (2019) argued that teachers were not effectively implementing the curriculum because they were considered as mere classroom teachers who could not play any other role in the curriculum development process. If teachers are not adequately involved in the entire curriculum process, the chance of reducing the gap between the intended and achieved curriculum becomes almost impossible. This is the case because teachers are key in any curriculum implementation process. Teachers therefore need to have a thorough understanding of the entire curriculum starting with curriculum intent if they are to interpret it correctly to the learners in the classroom. It is on this basis that Mwanza (2019) advocated for full teacher involvement in curriculum development teams. In addition, Mwanza and Changwe (2020) explained that teachers in Zambia were dissatisfied with the existing practice of curriculum development which insignificantly involved them. If this scenario remains unchecked, the gap between the intended and the achieved curriculum will remain wide as teachers risk misinterpreting the curriculum due to lack of adequate comprehension of the curriculum intent and content. Thus one of the ways of motivating teachers as key stakeholders in the curriculum development process is to create a conducive environment for them to effectively play their respective roles of being; curriculum developer, curriculum adapter or modifier, researcher as well as curriculum implementer (Print, 1993). If such best practices were to be effected in the country, it would be very likely that teachers would own the 
developed curriculum and ensure that it is effectively implemented thereby reducing the gap between the intended and achieved curriculum.

Besides, teachers who are handsomely paid their monthly salaries would adhere and respect the eight hours working policy. Meaning teachers are likely to have long contact hours with the learners which would enhance effective implementation of the curriculum. Mkandawire (2010) explained that lack of accommodation and poor salaries were enough to demoralise teachers who in most cases resorted to go into private commercial enterprises to supplement inadequate salaries. After wedge freeze, the government of the republic of Zambia in the year 2019 gave teachers a salary increment of $4 \%$ which most stakeholders described as a drop in the ocean. Despite the complaints that the general public were registering regarding higher taxes that were remitted on monthly basis to the national treasury, in the same year the government introduced a $1 \%$ national health insurance bill. This new tax meant that teachers only had an increment of 3\%. Similarly, in the year 2020 teachers were still dissatisfied with the $8 \%$ salary increment which could have been due to the daily loss of value of Zambia's national currency. In the midst of such challenges, it was very difficult for the teacher to effectively implement the curriculum. It was therefore necessary for the responsible ministry in government to look at the welfare of teachers by ensuring that their working conditions are improved if quality implementation of the curriculum countrywide were to be realised.

Teachers countrywide had upgraded their professional qualifications from certificates to diploma and others to first and second (masters) degrees. When a teacher upgrades his/her qualifications, there is always the hope of having their salaries reconsidered so that the concerned staffs are motivated to even work extra hard. This was not the case in Zambia as most of the teachers who had upgraded their professional qualifications felt demotivated when their salaries remained unchanged several years after investing the little they were earning to pay for their college/university tuition fees. This was another serious issue that the relevant responsible ministry in government needed to address if teachers were to be motivated and eventually play a role in ensuring the effective implementation of the curriculum. Mulenga and Kabombwe (2019) reflected on the competence based curriculum which Zambia had adopted. The scholars wondered how such a demanding curriculum would be implemented when the budgetary allocation of funds to the Ministry of General Education and skills sector kept on reducing since 2015 as follows; 2015 (20.2\%), 2016 (17.2\%), $2017(16.5 \%)$ and $2018(16.1 \%)$. The same trend was noticed in subsequent years, for instance, the budgetary allocation for the year 2020 and 2021 to the education sector were $12.4 \%$ and $11.5 \%$ respectively. The duo and in line with UNICEF (2016) argued that despite such budgetary allocation, a very big percentage say about $81 \%$ of the total education budget was not used to procure teaching and learning materials but to pay salaries of teachers and other educational personnel. Based on this argument, it was clear that Zambia was not likely to effectively implement the competence based curriculum because such a curriculum requires good funding for schools to have appropriate teaching and learning materials.

\subsection{National Examinations and Time Management}

Assessment is an integral part and parcel of the teaching and learning process. In order for the nation to be in a position to know the extent to which learners have acquired the desirable knowledge, values, attitudes and skills, there is need to employ various forms of assessments namely; diagnostic, formative and summative assessments. Despite the importance of national examinations in the teaching and learning process, if not well managed it would turn to be a barrier to the effective implementation of the curriculum. For instance, Ogula (1998: 84) explained that "an assessment that puts too much emphasis on the testing of cognitive skills tend to promote rote learning in the schools." This means that teachers may resort to simply teach for learners to pass national examinations and not necessarily for acquiring the worthwhile knowledge, values, attitudes and skills. It is in this regard that national examinations can be considered to be a barrier to the effective implementation of the curriculum that is meant to produce learners who would play critical roles in solving societal problems and eventually contribute to the economic growth of the country.

It is worthwhile arguing that despite the school in-house policy of awarding teachers who produce very good results in national examinations being very cardinal, at times this may negatively affect the way classroom teaching is expected to be conducted. For instance, in trying to record very high pass percentage, teachers may normally resort to drilling learners on how to answer specific questions which subject teachers are very sure of appearing in the final national examinations at the expense of other vibrant sections of the curriculum.

In addition, it had been a common practice in Zambia for national examinations to take three quarters of the teaching and learning time in the third term of every academic year. In schools where classrooms are inadequate, non-examination classes were asked to close earlier in order to create enough rooms in which to conduct national examinations. This is a serious problem more especially to the curriculum specialist who understands the importance of time resource in the curriculum development process. In their study, Mulenga and Lubasi (2019) considered the utilisation of time resource in the teaching and learning programmes in Mongu district of Zambia. The study revealed that although teachers would be present in school, they spent most of the time attending to non-classroom teaching activities such as organising learners in sports, staff meetings and invigilation of national examinations. This may lead to the conclusion that several non-teaching factors affected effective utilisation of learning time in the implementation of the curriculum. 
Mulenga and Lubasi (2019) wondered why too much of the learning time could be spent on assessment of learning instead of assessment for learning. The two scholars argued that effective learning should in all sense precede summative assessment because assessment was meant to service learning. Based on the effective utilisation of time, Ugwulashi (2013) contended that it is impossible to have educational goals achieved when time management is poor. All these studies have shown that poor management of time though ignored amongst the factors that affects effective implementation of the curriculum can be detrimental to the quality of education being provided to learners which may eventually lead to fail to realise educational goals and aims of the country. Thus the recommendations made by Mulenga and Lubasi (2019) where they requested the Ministry of General Education in Zambia to revisit the national examination time tabling strategy so as to reduce on the learning time that was being lost as well as the school administrators to closely monitor teachers to ensure that they are in class on time remain valid best practices of bridging the gap between the intended and the achieved school curriculum. Of course there is also urgent need for school administrators as they monitor time management amongst the teaching staff to ensure that there is adequate teacher preparation in terms of schemes of work, lesson plans as well as records of work that truly reflects what transpired during the teaching and learning process.

In addition to what has been discussed as impediments to curriculum implementation, political influence and pressure is another serious issue that requires adequate attention. It is a common practice for the party in government to ensure that their party manifesto is implemented. Unfortunately, if one of their manifestos is to alter the way education is being provided, most politicians tend rush the process of developing and implementing the curriculum even when there is no adequate human and non-human resources. It is as a result of rushing the curriculum development process that may lead to what has being explained in preceding sections where the curriculum is implemented in schools amidst poor quality of teaching and learning materials. For instance, Computer Studies in Zambian secondary schools was implemented when schools had no adequate human and teaching resources as revealed by Changwe and Mulenga (2020). Besides, the study by Musilekwa and Mulenga (2019) revealed that privatization of textbook development, lack of coordination between the Curriculum Development Centre and textbook publishing companies as well as the political interference in textbook development had contributed to poor quality textbook development. For example, Musilekwa and Mulenga (2019) noted that the Social Studies textbook had a lot of spelling mistakes and other errors for instance, instead of writing 'the Provincial Headquarters of Southern Province' it was written as 'the capital city of Southern Province' which was wrong.

In conclusion, it is worthwhile affirming that the gap between the intended and the achieved curriculum may continue to affect the quality of education in learning institutions across the world and Zambia in particular if serious measures are not put in place to address the cited impediments to curriculum implementation. Namely; economic conditions, the quality and quantity of the teaching staff, motivation among the curriculum implementers as well as national examinations and time management. The identified gaps can be addressed by improving the country's economy which in a long run would enhance; appropriate school infrastructure and equipment, adequate supply of teaching and learning resources both human and non-human, spending enough time on assessment for learning rather than on assessment of learning as well as through the reintroduction of the feeding programme in schools.

\section{REFERENCES}

[1] Bishop, G. (1985). Curriculum Development: A Textbook for Students. London: The Macmillan Press.

[2] Changwe, R. (2017). Effectiveness of the Mathematics Teacher Education Curriculum at the University of Zambia in Preparing Secondary School Teachers of Mathematics. Masters Dissertation. The University of Zambia.

[3] Changwe, R. \& Mulenga, C. L. (2020). Teaching and Learning Resources and Teachers for the Implementation of Computer Studies Curriculum in Selected Public Primary Schools in Ndola District of Zambia. European Journal of Education Studies, 7(10), 97-118.

[4] Changwe, R. Mulenga, I. M. (2018). Mathematics Teacher Education Curriculum at a University in Zambia: Student Teachers' Acquisition of Appropriate Competencies for Teaching Mathematics in Secondary School. Multidisciplinary Journal of Language and Social Sciences Education. 1(1), 207-242.

[5] Fullan, M. \& Pomfert, A. (1977). Research on Curriculum and Instruction Implementation. Review of Educational Research, 47(1), 335-397. http://www.ibe.unesco.org/en/glossarycurriculum-terminology/i/intended-curriculum.

[6] Kelly, M. J. (1999). The Development of Education in Zambia. Lusaka: Image Publishers Limited.

[7] Ministry of Education. (1992). Focus on Learning. Lusaka: Government Printer.

[8] Mkandawire, S. B. (2010). Impediments (challenges) to Curriculum Implementation in Learning Institutions. Retrieved from https://sitwe.wordpress.com/2010/12/103/challenges-ofcurriculum-impediments-in-learning-institutions/ on 20/08/19.

[9] Mulenga, I. M. (2018). Conceptualisation and Definition of a Curriculum. Journal of Lexicography and Terminology. 2(2), 123.

[10] Mulenga, I. M. \& Kabombwe, Y. M. (2019). A CompetencyBased Curriculum for Zambian Primary and Secondary Schools: Learning from Theory and some Countries around the World. International Journal of Education Research. 7(2), 117-130.

[11] Mulenga, I. M. \& Lubasi, I. M. (2019). Teachers Present in School but Absent in Class: Utilisation and 'Silent Erosion' of Learning Time in the Implementation of the Curriculum in Mongu District of Zambia. European Journal of Education Studies. 6(2), 61-79. http://dx.doi.org/10.5281/zenodo.2678061.

[12] Musilekwa, S. \& Mulenga, I. M. (2019). Development of Social Studies Learners' Textbooks for Secondary Schools in Zambia. Journal of Education and Practice. 10 (6), 99-108. Doi:10.7176/JEP.

[13] Mwanza, C. (2017). Teacher Involvement in Curriculum Development in Zambia: A role Analysis of Selected School Teachers in Lusaka District. Lusaka province, Zambia. Masters Dissertation. The University of Zambia.

[14] Mwanza, C. \& Changwe, R. (2020). Teacher Collaboration in Curriculum Design Teams: Prospects and Challenges in the Zambian Education System. Multidisciplinary Journal of 
Language and Social Sciences Education. 3(1), (pub. 20.02.2020), 181-204.

[15] Nkosha, D. C. \& Mwanza, P. (2009). Quality of Basic Education Provided by Rural Community and Regular Schools in the Northern Province of Zambia. Journal of International cooperation in Education, 12(1), 19-32.

[16] Ogula, P. A. (1998). A Handbook on Curriculum Development. Nairobi: New Kemit Publishers.

[17] Okello, V. and Kagoire, M. A. (1996). Makerere University Curriculum Studies Module. Kampala: Bezatel Design Studies.

[18] Omondi, M. P. (2014). Factors Influencing the Implementation of Curriculum in Public Primary Schools in Ukwala Division of Siaya. Nairobi: University of Nairobi Press.
[19] Print, M. (1993). Curriculum Development and Design (2 ${ }^{\text {nd }}$ Edition). Sydney: Allen \& Unwin Pty Ltd.

[20] Shiundu, J. S. \& Omulando, S. J. (1992). Curriculum: Theory and Practice in Kenya. Nairobi: Oxford University Press.

[21] Sibulwa, C. M. (1996). Selected Reading Materials and Notes. EAP 111 Batch 3. Lusaka: Directorate of Distance Education.

[22] Tanner, D. \& Tanner, L. N. (1980). Curriculum Development: Theory into Practice. New York: Macmillan.

[23] Wanjiru, J. (2008). Factors Influencing Effective Implementation of Curriculum in Kamkunji Kenya. Nairobi: University of Nairobi Press. Zambia Daily Mail, 27 2017. 